\title{
STUDIES OF COPROPORPHYRIN. I. THE PER DIEM EXCRETION AND ISOMER DISTRIBUTION OF COPROPORPHYRIN IN NORMAL HUMAN URINE ${ }^{1}$
}

\author{
By CECIL JAMES WATSON, VIOLET HAWKINSON, SAMUEL SCHWARTZ, \\ AND DONALD SUTHERLAND
}

(From the Department of Medicine, University of Minnesota, Minneabolis)

(Received for publication July 9, 1948)

A recent review (1) has dealt with previous studies of the urinary coproporphyrins, both as carried out in this laboratory and elsewhere. The purpose of the present series of communications is to provide newer data relating to various aspects of the coproporphyrin problem.

It is well known that two of the four coproporphyrin isomers occur in human urine (1). These naturally occurring isomers are types $I$ and III according to $\mathrm{H}$. Fischer's classification, as based upon the configuration of the four artificial aetioporphyrins (2). Apart from the difference displayed by the two isomers in ester melting point and crystal habitus, a differing physical behavior has been described as manifested in their $\mathrm{pH}$ fluorescence curves. This difference was first noted by Hoerburger and Fink (3-5) who attempted to apply it to the coproporphyrin of normal urine. The crystal habitus and $\mathrm{pH}$ fluorescence curve of the few crystals which they obtained indicated the presence of coproporphyrin I (5). A later study by Watson (6) was likewise somewhat indecisive in that the melting point of the crystalline ester was $228^{\circ} \mathrm{C}$, that of pure coproporphyrin I methyl ester being $252^{\circ} \mathrm{C}$ (corrected), as contrasted with the varying or dimorphic melting point of the esters of coproporphyrin III : $134^{\circ}$, $142^{\circ}, 168^{\circ}(2)$. The crystal habitus in this study also, was that of the type $I$ isomer, and it was therefore concluded that in the urine employed, which was from one normal individual, the preponderant coproporphyrin was type I. At the same time it was believed that a small amount of the type III isomer was present, since a few rosettes of prisms having the type III habitus were obtained from the mother liquor. The weighed yield of crystals in

1 Aided by grants from the John and Mary R. Markle Foundation, New York City, and from the Medical Research Fund of the Graduate School, University of Minnesota, Minneapolis. this study was 0.13 mgm., obtained from 33 liters of urine. This had seemed a fair sized undertaking, but it was dwarfed by the subsequent investigation of Grotepass (7), in which 10,000 liters of presumably normal human urine were worked up with a yield of ca. $200 \mathrm{mgm}$. of crystalline coproporphyrin ester. Grotepass' method was to adsorb the porphyrin on infusorial earth, large containers being employed into which many individuals passed their urine, the urine simply being decanted after a period of contact with the earth. The porphyrin which was isolated after subsequent purification and fractional crystallization was found to consist of about equal parts of type I and III isomers, and it was therefore concluded that the normal urinary coproporphyrin consists of approximately equal parts of the two types. Certain reservations regarding this conclusion will be discussed subsequently.

During the past nine years studies have been in progress which were designed to provide a method of isomer analysis applicable to a small volume of urine and by means of which it would be possible to make a systematic study of the urinary coproporphyrin isomer excretion without recourse to isolation of the crystalline esters. A multitude of possibilities were explored relating in the main to differential solubilities, such as that of the methyl esters in cold methyl alcohol (8) or absolute ethyl ether (9), also to differential chromatographic behavior with various solvents and adsorbents. It was previously reported (10) that pure coproporphyrin III methyl ester was readily eluted from aluminum oxide (Brockmann) by $30 \%$ aqueous acetone, while the type I ester remains adsorbed, being eluted with pure acetone. After extensive preliminary purification this method was applicable only to the porphyrin from certain urine samples. A great many alternative preliminary treatments were tried in the hope that 
one might be found which would be uniformly applicable, but none were satisfactory. During these investigations, however, a new difference in physical behavior was discovered, i.e., that the red fluorescence in ultraviolet light exhibited by the type I methyl ester rapidly disappears in 30-35\% aqueous acetone, in the cold, while that of the type III ester persists (11). This phenomenon has been shown to be due to a differential rate of precipitation (12). It has been made the basis of two alternative procedures for analysis of isomer distribution, $A$ and $B$, which have been described in detail in separate communications $(11,12)$.

In the present study these procedures have been applied to a series of 24 hour urine samples from presumably normal healthy adults, in order to determine both total coproporphyrin and isomer percentage.

\section{MATERIAL AND METHODS}

Twenty-four hour urine samples were studied from 53 individuals. Thirty of these ranged in age from 19-30, ten from 30-64, and 13 from 65-86. Twenty-eight were males and 25 were females. Those between 19 and 30 in age were medical students, interns, technicians and physicians. Some of these undoubtedly had mild chemical exposure of the type encountered in a routine clinical laboratory, plus in a few instances, fumes of petroleum ether, ethyl ether, chloroform, and benzene, but in no instance was this believed to be of consequence. So far as can be determined, heavy metal exposure and alcoholism were excluded in the entire group, and there was no history of any chemical exposure in the older members of the group. The 24 hour urine samples were collected in large bottles without preservative.

Twenty-four hour urine samples were also collected from two groups of students in the Divinity School of the University of Chicago, the first a group of nine during May 1946, the second a different group of ten individuals during February 1948.2 Total coproporphyrin concentration and isomer distribution were likewise determined for each of these samples.

The method employed for the quantitative determination of the total coproporphyrin and isomer percentage has been described in detail elsewhere (12). Procedure A of the two alternative procedures, was used in the first 30 instances (individuals from 19 to 30 years of age). In addition procedure $B$ was applied to aliquots of the same 24 hour urines from 18 of these individuals. Procedure $B$ is somewhat simpler and less liable to error than A. Repeated determinations carried out on the same

2 We are indebted to Miss Elaine Katz of the Argonne National Laboratory, Chicago, for obtaining and sending us these samples. urine samples with the two procedures, have shown excellent agreement, as will be evident from data presented below.

As noted in an earlier paper (12), the fluorescence measurements have been made in a Klett fluorophotometer, using a fluorescein solution for the balanced photo cell. In this paper a typographical error unnoticed in correction of the proof, indicates that the fluorescein concentration is $3 \mathrm{Gm} . \%$, whereas the correct value is a $3 \mathrm{mgm} . \%$. This is an arbitrary concentration in any event which would have to be calibrated for any given instrument, against known concentrations of pure coproporphyrin.

Recently one of us (S.S.) has devised a simpler method for determination of the total urinary coproporphyrin, applicable to $5 \mathrm{cc}$. of urine. The results obtained with this procedure indicate that the true values for the UCP are approximately $20 \%$ higher than those obtained with the method (12) employed in the present study. This work will be described in a separate communication.

\section{RESULTS}

The results of the duplicate determinations with procedures $\mathrm{A}$ and $\mathrm{B}$ are given in Table I. From this it is evident that the two procedures are in good agreement.

TABLE I

Duplicate determinations with procedures $A$ and $B$

$\begin{array}{rcc}\text { No. } & \begin{array}{c}\text { \% type III by } \\ \text { Procedure A }\end{array} & \begin{array}{c}\text { \% type III by } \\ \text { Procedure B }\end{array} \\ 1 & 9 & 10 \\ 2 & 15 & 16 \\ 3 & 10 & 12 \\ 4 & 30 & 27 \\ 5 & 28 & 30 \\ 6 & 18 & 18 \\ 7 & 17 & 17 \\ 8 & 31 & 30 \\ 9 & 30 & 29 \\ 10 & 34 & 36 \\ 11 & 20 & 21 \\ 12 & 20 & 20 \\ 13 & 10 & 12 \\ 14 & 18 & 20 \\ 15 & 15 & 13 \\ 16 & 22 & 22 \\ 17 & 8 & 7 \\ 18 & 23 & 22\end{array}$

The data for the 53 individuals are given in Table II. As will be noted this table includes the values for the total urinary coproporphyrin (UCP) and the percentage of the two isomers. The frequency distribution of the UCP, and of each of the isomers, I and III, is shown in Figure 1.

The data for the Chicago Divinity students are given in Table III. 
TABLE II

Total UCP and isomer distribution in 53 normal subjects

\begin{tabular}{|c|c|c|c|c|c|c|}
\hline No. & Sex & Age & Occupation & $\begin{array}{l}\text { Total } \\
\text { UCP }\end{array}$ & $\%$ type & $\begin{array}{c}\% \text { type } \\
\text { III }\end{array}$ \\
\hline $\begin{array}{r}1 \\
2 \\
3 \\
4 \\
5 \\
6 \\
7 \\
8 \\
9 \\
10\end{array}$ & $\begin{array}{l}\mathbf{M} \\
\mathbf{M} \\
\mathbf{M} \\
\mathbf{M} \\
\mathbf{M} \\
\mathbf{M} \\
\mathbf{M} \\
\mathbf{M} \\
\mathbf{M}\end{array}$ & $\begin{array}{l}21 \\
22 \\
20 \\
23 \\
22 \\
22 \\
21 \\
21 \\
22 \\
25\end{array}$ & $\begin{array}{l}\text { Med. student } \\
\text { Med. student } \\
\text { Med. student } \\
\text { Med. student } \\
\text { Med. student } \\
\text { Med. student } \\
\text { Med. student } \\
\text { Med. student } \\
\text { Med. student } \\
\text { Pre-Med. student }\end{array}$ & \begin{tabular}{|c}
$\gamma / 24$ hrs. \\
80 \\
38 \\
85 \\
69 \\
57 \\
45 \\
42 \\
63 \\
74 \\
63
\end{tabular} & $\begin{array}{l}91 \\
85 \\
90 \\
70 \\
72 \\
82 \\
83 \\
69 \\
70 \\
66\end{array}$ & $\begin{array}{l}9 \\
15 \\
10 \\
30 \\
28 \\
18 \\
17 \\
31 \\
30 \\
34\end{array}$ \\
\hline $\begin{array}{l}11 \\
12 \\
13 \\
14 \\
15 \\
16 \\
17 \\
18 \\
19 \\
20\end{array}$ & $\begin{array}{l}F \\
F \\
F \\
F \\
F \\
F \\
F \\
F \\
F \\
F\end{array}$ & $\begin{array}{l}22 \\
21 \\
22 \\
28 \\
19 \\
25 \\
20 \\
22 \\
22 \\
20\end{array}$ & $\begin{array}{l}\text { Med. student } \\
\text { Med. technician } \\
\text { Med. technician } \\
\text { Med. technician } \\
\text { Nurse } \\
\text { Med. technician } \\
\text { Med. technician } \\
\text { Med. technician } \\
\text { Med. technician } \\
\text { Med. technician }\end{array}$ & $\begin{array}{l}25 \\
46 \\
58 \\
63 \\
25 \\
99 \\
69 \\
70 \\
75 \\
59\end{array}$ & $\begin{array}{l}80 \\
80 \\
83 \\
79 \\
79 \\
90 \\
82 \\
85 \\
78 \\
92\end{array}$ & $\begin{array}{r}20 \\
20 \\
17 \\
21 \\
21 \\
10 \\
18 \\
15 \\
22 \\
8\end{array}$ \\
\hline $\begin{array}{l}21 \\
22 \\
23 \\
24 \\
25 \\
26 \\
27 \\
28 \\
29 \\
30\end{array}$ & $\begin{array}{l}\mathbf{F} \\
\mathbf{M} \\
\mathbf{M} \\
\mathbf{M} \\
\mathbf{M} \\
\mathbf{M} \\
\mathbf{M} \\
\mathbf{F} \\
\mathbf{F}\end{array}$ & $\begin{array}{l}20 \\
25 \\
23 \\
23 \\
23 \\
27 \\
27 \\
23 \\
22 \\
30\end{array}$ & $\begin{array}{l}\text { Med. technician } \\
\text { Med. student } \\
\text { Med. student } \\
\text { Med. student } \\
\text { Med. student } \\
\text { Med. student } \\
\text { Med. student } \\
\text { Med. student } \\
\text { Student } \\
\text { Nurse }\end{array}$ & $\begin{array}{l}73 \\
93 \\
65 \\
17 \\
38 \\
79 \\
49 \\
52 \\
43 \\
28\end{array}$ & $\begin{array}{l}77 \\
65 \\
91 \\
92 \\
80 \\
87 \\
78 \\
81 \\
78 \\
82\end{array}$ & $\begin{array}{r}23 \\
35 \\
9 \\
8 \\
20 \\
13 \\
22 \\
19 \\
22 \\
18\end{array}$ \\
\hline $\begin{array}{l}31 \\
32 \\
33 \\
34 \\
35 \\
36 \\
37 \\
38 \\
39 \\
40\end{array}$ & $\begin{array}{l}F \\
M \\
M \\
F \\
F \\
M \\
F \\
F \\
F \\
M\end{array}$ & $\begin{array}{l}59 \\
62 \\
57 \\
45 \\
52 \\
70 \\
65 \\
40 \\
38 \\
42\end{array}$ & $\begin{array}{l}\text { Housewife } \\
\text { Pathologist } \\
\text { Pathologist } \\
\text { Housewife } \\
\text { Housewife } \\
\text { Businessman } \\
\text { Housewife } \\
\text { Teacher } \\
\text { Housewife } \\
\text { Businessman }\end{array}$ & $\begin{array}{l}26 \\
90 \\
28 \\
58 \\
76 \\
67 \\
79 \\
45 \\
40 \\
50\end{array}$ & $\begin{array}{l}79 \\
70 \\
78 \\
80 \\
62 \\
60 \\
62 \\
84 \\
80 \\
82\end{array}$ & $\begin{array}{l}21 \\
30 \\
22 \\
20 \\
38 \\
40 \\
38 \\
16 \\
20 \\
18\end{array}$ \\
\hline $\begin{array}{l}41 \\
42 \\
43 \\
44 \\
45 \\
46 \\
47 \\
48 \\
49 \\
50 \\
51 \\
52 \\
53\end{array}$ & $\begin{array}{l}\mathbf{F} \\
\mathbf{F} \\
\mathbf{F} \\
\mathbf{M} \\
\mathbf{F} \\
\mathbf{F} \\
\mathbf{M} \\
\mathbf{F} \\
\mathbf{M} \\
\mathbf{M} \\
\mathbf{M} \\
\mathbf{M}\end{array}$ & $\begin{array}{l}33 \\
30 \\
82 \\
69 \\
86 \\
73 \\
75 \\
84 \\
78 \\
82 \\
79 \\
86 \\
82\end{array}$ & $\begin{array}{l}\text { Librarian } \\
\text { Nurse } \\
\text { Old people's home } \\
\text { Old people's home } \\
\text { Old people's home } \\
\text { Old people's home } \\
\text { Old people's home } \\
\text { Old people's home } \\
\text { Old people's home } \\
\text { Old people's home } \\
\text { Old people's home } \\
\text { Old people's home } \\
\text { Old people's home }\end{array}$ & $\begin{array}{l}65 \\
41 \\
56 \\
66 \\
37 \\
36 \\
25 \\
90 \\
36 \\
36 \\
62 \\
43 \\
28\end{array}$ & $\begin{array}{l}71 \\
68 \\
62 \\
48 \\
72 \\
68 \\
58 \\
63 \\
54 \\
66 \\
73 \\
59 \\
84\end{array}$ & $\begin{array}{l}29 \\
32 \\
38 \\
52 \\
28 \\
32 \\
42 \\
37 \\
46 \\
34 \\
27 \\
41 \\
16\end{array}$ \\
\hline
\end{tabular}

\section{DISCUSSION}

The present results are in accord with the earlier indications of Hoerburger and Fink $(3,4)$, and of Watson (6) that the type $I$ isomer is pre-
TABLE III

Total coproporphyrin and isomer distribution in 24 hour urine samples from Divinity students

\begin{tabular}{|c|c|c|c|c|c|c|c|}
\hline \multicolumn{4}{|c|}{ Group 1. May 1946} & \multicolumn{4}{|c|}{ Group 2. Feb. 1948} \\
\hline No. & $\begin{array}{l}\text { Total } \\
\text { UCP }\end{array}$ & $\underset{\text { type }}{\%}$ & $\begin{array}{c}\% \\
\text { type } \\
\text { IIII }\end{array}$ & No. & $\begin{array}{l}\text { Total } \\
\text { UCP }\end{array}$ & $\begin{array}{c}\% \\
\text { type } \\
I\end{array}$ & $\begin{array}{c}\% \\
\text { type } \\
\text { III }\end{array}$ \\
\hline $\begin{array}{l}1 \\
2 \\
3 \\
4 \\
5 \\
6 \\
7 \\
8 \\
9\end{array}$ & $\begin{array}{c}\gamma / 24 \text { hrs. } \\
40 \\
110 \\
71 \\
88 \\
76 \\
87 \\
47 \\
13 \\
56\end{array}$ & $\begin{array}{l}18 \\
21 \\
24 \\
20 \\
42 \\
32 \\
26 \\
22 \\
23\end{array}$ & $\begin{array}{l}82 \\
79 \\
76 \\
80 \\
58 \\
68 \\
74 \\
78 \\
77\end{array}$ & $\begin{array}{r}1 \\
2 \\
3 \\
4 \\
5 \\
6 \\
7 \\
8 \\
9 \\
10 \\
11\end{array}$ & $\begin{array}{c}\gamma / 24 \text { hrs. } \\
80 \\
54 \\
60 \\
46 \\
68 \\
48 \\
126 \\
40 \\
25 \\
55 \\
54\end{array}$ & $\begin{array}{l}82 \\
88 \\
78 \\
79 \\
85 \\
82 \\
56 \\
84 \\
82 \\
69 \\
78\end{array}$ & $\begin{array}{l}18 \\
12 \\
22 \\
21 \\
15 \\
18 \\
44 \\
16 \\
18 \\
31 \\
22\end{array}$ \\
\hline
\end{tabular}

ponderant in normal human urine. They do not support Grotepass' conclusion (7) that the type III isomer composes approximately half of the normal urinary coproporphyrin. As pointed out by Dobriner and Rhoads (13), Grotepass' study is subject to the criticism that if but one abnormal individual contributed to the pooled urine which he studied, an erroneous conclusion might easily have been drawn with respect to the entire group. In a later paper of this series two cases will be described in some detail in which a latent, entirely symptomless, idiopathic coproporphyrinuria exists. These individuals' 24 hour urines usually contain 1-4 mgm. of coproporphyrin III. Similarly, an individual with latent plumbism excretes markedly increased amounts of coproporphyrin III, not infrequently ranging from 0.5 to $1.5 \mathrm{mgm} . /$ day. ${ }^{3}$ Thus, in a study of the type conducted by Grotepass, it is evident that a considerable error might be introduced by a relatively small contribution of urine from one or more individuals with latent or unrecognized abnormality. Nevertheless, a "geochemical" difference must also be considered and, in fact, the recent study by Schwartz and his associates (14) in Chicago offers support for such a possibility. In this study the urines of a "control" or supposedly normal group of individuals were regularly found to contain more than $50 \%$ of the type III isomer, usually from 60 to $85 \%$. It was at first believed that this might be accounted for by occupational chemical or heavy metal exposure,

\footnotetext{
3 Unpublished data.
} 


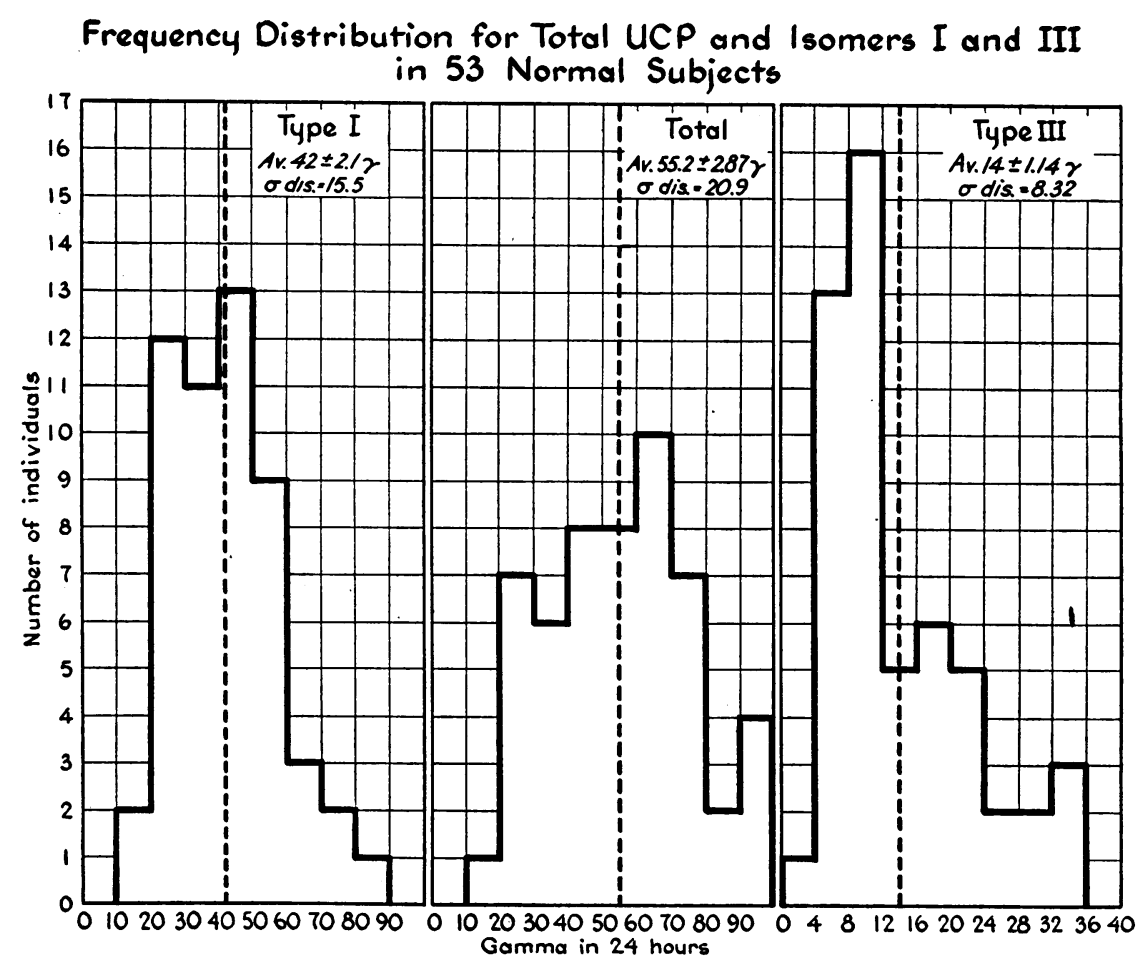

FIG. 1

or use of alcohol, but later members of the group who exhibited the same increases of the type III isomer were students in the Divinity School who had no known exposure to metals or chemicals which might produce abnormality.

In order to be doubly certain on this point, samples were collected in May 1946, from a group of nine of these students (Group 1 in Table III), and were sent to this laboratory for the isomer analysis with the results which have been given in Table III. These may be contrasted with data obtained in February 1948, from another group of 11 students at the same school. Unfortunately, it was not possible to obtain samples again from any of the individuals of the 1946 study. There is every reason to assume, however, that the habits and environment of the two groups were essentially the same. The only known difference of possible significance was the installation of a new city water filtration system for that area of Chicago, early in 1947. Thus there is the possibility that a change in water supply was responsible for the rather striking reversal in isomer ratio noted in Table III. Other possibilities, however, are not excluded, and further studies in other areas, both urban and rural, would be of interest with relation to such factors as water supply, air contamination and occupational or environmental chemical exposure.

In the meanwhile it is evident from the present data that a preponderance of the type $\mathrm{I}$ isomer is characteristic of normal adults in the Minneapolis area. It is believed that this should be regarded as the norm, since it is well established that heavy metal or chemical intoxication even though of such mild degree as to be symptomless, nevertheless causes significant increases of the type III isomer. This will be considered in a subsequent paper, in relation to the effect of alcoholism. The phenomenon of reversal of the isomer ratio within a normal total value, has been noted in certain of the "control" personnel studied by Schwartz and associates (14). The relative or even absolute decrease of type $I$ isomer in these instances points to a closer relationship between the two isomers than hitherto entertained. Although not necessarily reciprocal, the relationship appears to be one of a balanced production normally favoring type $I$, but 
easily upset in favor of type III by chemicals, metals and possibly other factors which will be discussed in subsequent papers.

In so far as the study of any given individual or group of cases in one area is concerned, it is recognized that before conclusions could be drawn as to the significance of reversal of the isomer ratio, it would be necessary to establish the ratio for presumably normal individuals in that area. With the method used (12), it is believed that where increases above a total of $100 \gamma$ are encountered, values of $40 \%$ or more of type III isomer may probably be regarded as abnormal even though control data for that area are not available.

In animal studies it is likewise possible that local differences will be found to prevail. Our own observations (in both Minneapolis and Chicago) have thus far indicated that the type III isomer comprises about $80 \%$ of the total in urine from healthy rabbits, and about $50 \%$ from that of healthy dogs. Whether this higher ratio of type III is due to metal or chemical contamination of the diet, as for example, from the cages, has not been determined.

\section{SUMMARY AND CONCLUSIONS}

1. The total urinary coproporphyrin (UCP) and the isomer distribution have been studied by means of the differential precipitation, or "fluorescence quenching" method, in 24 hour urine samples of 53 presumably normal adult humans of both sexes, living in Minneapolis and ranging in age from 18 to 86 .

2. The UCP in this group ranged from 17 to $99 \gamma / 24$ hrs., with an average of $55.2 \pm 2.87 \gamma$.

3 . The percentage of type III isomer was 40 or higher in five of the $\mathbf{5 3}$ individuals. In three of these it was from 46 to $52 \%$. In 48 it was less than $40 \%$ and of these, 43 were below $35 \%$. In terms of gamma/day the type III isomer ranged from 1.3 to 34.4 , with an average of $14 \pm 1.14 \gamma$.

The type I values ranged from $14.5-89.1 \gamma$ with an average of $42 \pm 2.1 \gamma$.

4. Twenty male Divinity students, living in the area of the University of Chicago, were also studied as to total UCP excretion and isomer distribution. Samples from the first group of nine were obtained in May 1946. These contained from 58 to $82 \%$ of type III isomer within a normal value for total UCP. The second group of 11 was studied in February 1948; in these the range was 56 to $88 \%$ of type I isomer. The possibility is considered that a change in the water supply in 1947 may explain the return to the normal ratio.

\section{BIBLIOGRAPHY}

1. Watson, C. J., and Larson, E. A., The urinary coproporphyrins in health and disease. Physiol. Rev., 1947, 27, 478.

2. Fischer, H., and Orth, H., Die Chemie des Pyrrols. Akadem. Verlagsgesellsch., 1937, Leipzig, Band II, 1 Hälfte.

3. Hoerburger, W., Inaug. Diss., Erlangen, 1933.

4. Hoerburger, W., and Fink, H., Uber Porphyrine bei klinischer Porphyrie. Ztschr. f. physiol. Chem., 1935, 236, 136.

5. Fink, H., and Hoerburger, W., Isolierung von kristallisiertem Koproporphyrin I aus normalen menschlichen Urin. Naturwissensch., 1934, 22, 292.

6. Watson, C. J., Concerning the naturally occurring porphyrins IV. The urinary porphyrin in lead poisoning as contrasted with that excreted normally and in other diseases. J. Clin. Invest., 1936, 15, 327.

7. Grotepass, W., Zur Kenntnis der Natürlichen Harnporphyrine. Ztschr. f. physiol. Chem., 1938, 253, 276.

8. Dobriner, K., Porphyrin excretion in the feces in normal and pathological conditions. J. Biol. Chem., 1937, 120, 115.

9. Rimington, C., and Hemmings, A. W., Porphyrinuria following sulphanilamide: sulphanilamide dermatitis. Lancet, 1938, 1, 770.

10. Watson, C. J., and Schwartz, S., A method of separating small quantities of the coproporphyrin isomers 1 and 3. Proc. Soc. Exper. Biol. \& Med., 1940, 44, 7.

11. Schwartz, S., Hawkinson, V. E., and Watson, C. J., Quantitative differentiation of minute amounts of the coproporphyrin isomers (I and III) based on fluorescence behavior. Science, 1946, 103, 338.

12. Schwartz, S., Hawkinson, V., Cohen, S., and Watson, C. J., A micromethod for the quantitative determination of the urinary coproporphyrin isomers (I and III). J. Biol. Chem., 1947, 168, 133.

13. Dobriner, K., and Rhoads, C. P., The porphyrins in health and disease. Physiol. Rev., 1940, 20, 416.

14. Schwartz, S., Biochemical studies relating to the effects of radiation and metals. National Nuclear Energy Series (MPTS). Vol. 20, Pt. I, A. In press. 